\title{
AS AMERICAN GIRLS: MIGRACÃOO, SEXO E STATUS IMPERIAL EM 1918
}

\author{
Thaddeus Gregory Blanchette \\ Centro Universitário Augusto Motta - Brasil
}

\author{
Ana Paula da Silva \\ Centro Universitário Augusto Motta - Brasil
}

Resumo: O presente trabalho, baseado em pesquisas históricas nos documentos do Consulado Americano no Rio de Janeiro, analisa um caso envolvendo a prostituição de mulheres estadunidenses naquela cidade, em 1918. Taxadas pelo cônsul americano como "escravas brancas", as dançarinas da companhia de burlesque Baxter and Willard Company quase foram expulsas do Brasil por causa de suas atividades como prostitutas. Analisamos a história delas à luz das pressões políticas e sociais da época. Dedicamos atenção particular sobre como as novas tecnologias de controle da circulação internacional (passaportes) se combinavam com o pânico social sobre a escravidão branca e os projetos políticos dos EUA frente às Américas. Nesse caso, a retórica sobre a proteção das vulneráveis foi utilizada para tentar bloquear a migração de mulheres “impuras” cujas ações e atitudes expuseram os Estados Unidos ao ridículo.

Palavras-chave: escravidão branca, tráfico das mulheres, Brasil, Estados Unidos.

\begin{abstract}
The present study, based on historical research into the archives of the American Consulate in Rio de Janeiro, Brazil, analyzes a case involving the prostitution of American women in that city in 1918. Labeled "white slaves" by the American Consul General, the dancers of the Baxter and Willard Company burlesque troop were almost expelled from Brazil due to their activities as prostitutes. Here, we analyze their story in the light of contemporary political and social pressures. We pay special attention to how new technologies controlling international movements (passports) combined with the social panic regarding white slavery and the political projects of the U.S. in Latin America. In this case, the rhetoric of protecting the vulnerable was utilized to block the migration of "impure" women whose actions and attitudes exposed the U.S. to ridicule.
\end{abstract}

Keywords: white slavery, trafficking of women, Brazil, United States. 
As endiabradas american girls do Theatro Phenix tem revolucionado parte da nossa jeunesse dorée. Louras na maioria, quasi todas fausses maigres, exhibindo á vontade as pernas, as buliçosas dansarinas tem tido um successo sem precedente no Rio.

Revista Fon-Fon, $1^{\circ}$ de dezembro de 1917.

Mr. Rowley,

Penso que devemos ser rigorosos e difíceis na emissão de passaportes para vagabundas dessa estirpe, especialmente quando elas estão viajando para os países da América Latina.

Memorando do Bureau of Citizenship dos EUA, 2 de janeiro de 1918.

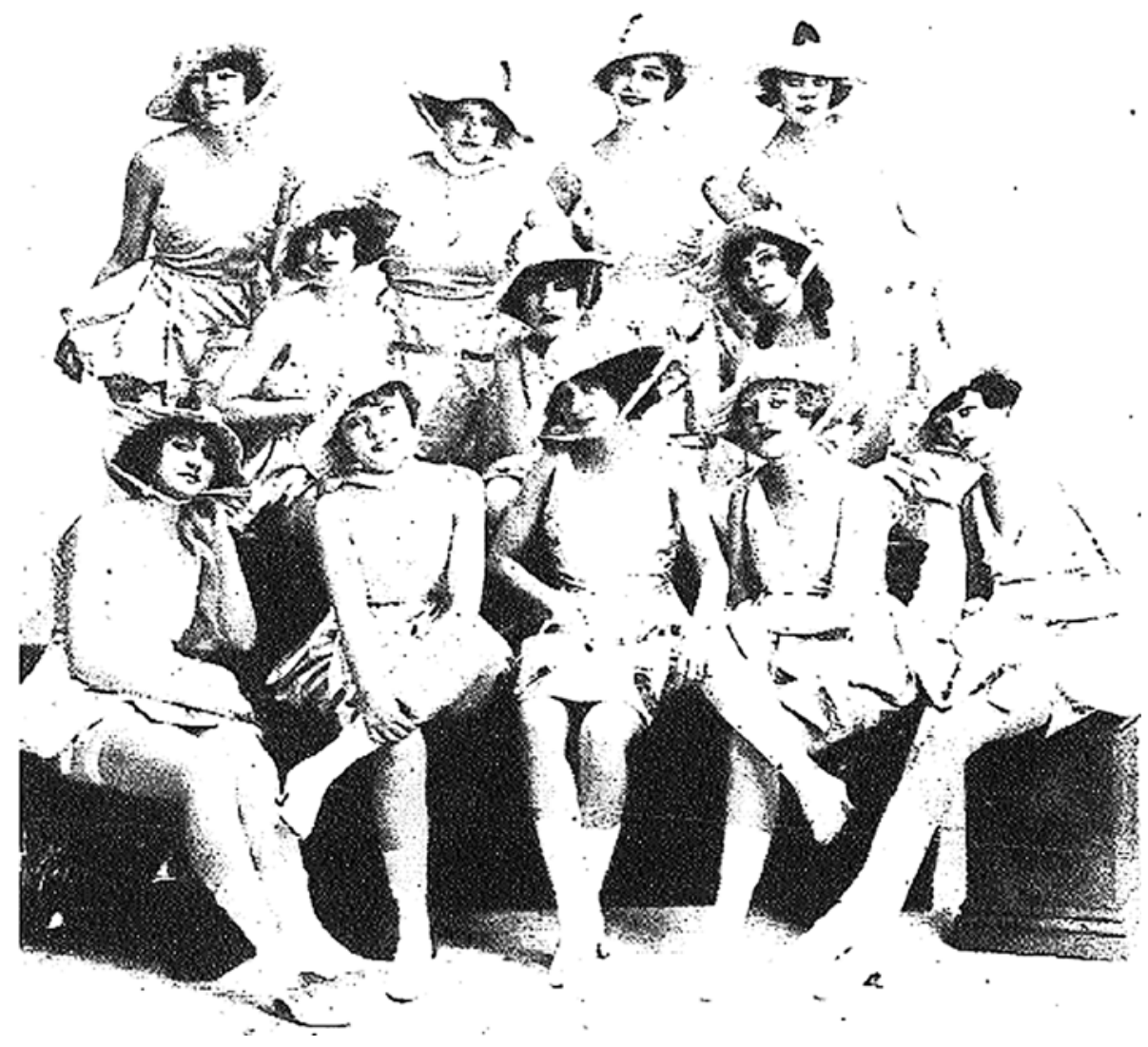

Figura 1. As American girls fazem pose para a revista fon-fon (1917a, p. 30).

Horizontes Antropológicos, Porto Alegre, ano 15, n. 31, p. 75-99, jan./jun. 2009 
A mulher solteira - especialmente se for jovem - ocupa um espaço privilegiado nos discursos sobre os perigos da imigração. Em primeiro lugar, ela costuma ser apresentada como alguém que seria exposta às ameaças da escravidão sexual, uma vez estando ela fora da rede protetora da família e longe do olhar do governo de seu país de nascimento. Nesse sentido, seu projeto imigratório é tido como algo que representa um perigo à sua pureza e liberdade, essas duas características sendo sempre articuladas com relacionamentos sexualmente monogâmicos sancionados pelo Estado e/ou a Igreja.

Mas a jovem solteira e imigrante é também entendida como um perigo à nação. Seu deslocamento internacional representa um perigo tanto para o país de recepção quanto para o país de origem. No primeiro caso, ela é vista como uma fonte de possíveis "maus costumes" e/ou ameaças biológicas (doenças venéreas, miscigenação, etc.), essas quase sempre relacionadas ao seu comportamento sexual. No segundo caso, ela é uma ameaça em potencial ao status de seu país de origem, alguém cujo comportamento (e particularmente seu comportamento sexual) pode macular a reputação de sua terra natal. Em destaque particular nesse quadro encontra-se a prostituta,${ }^{1}$ tida como o casolimite de migração feminina. Enquanto todas as jovens desacompanhadas são suspeitas, a trabalhadora sexual declarada, em muitos casos, é sumariamente proibida de deslocar-se internacionalmente e atrai todo tipo de vigilância e repressão.

Mas em suas tentativas de controlar as fronteiras, proteger seus cidadãos e salvaguardar a nação, como é que o Estado pode determinar quem é puta e quem não é? Como analistas do tema do sexo comercializado e migrações internacionais têm observado (Augustín, 2007; Brennan, 2004; Piscitelli, 2004; Silva; Blanchette, 2005, entre muitos outros), a prostituição é, acima de tudo, um comportamento e não uma categoria fixa de identidade. Ao que parece, em vez de descobrir prostitutas em trajetórias de migração, o Estado as inventa. Numa maneira análoga àquela desvendada por Bruno Latour (2000) em seu estudo sobre laboratórios científicos, o Estado aplica um conceito moral e po-

\footnotetext{
Entendemos como prostituta a mulher que vende comercialmente serviços sexuais. Também usamos como sinônimos trabalhadora sexual e puta. Todos os três termos são usados como categorias êmicas, nativas tanto do universo do sexo comercializado, quanto do universo dos agentes que tentam controlar os fluxos migratórios de mulheres solteiras.
} 
lítico previamente formado (prostituta) a uma grande gama de mulheres que podem ou não estar se prostituindo.

Embora ambas as nações receptoras e originárias das migrações tentem identificar e impedir os fluxos migratórios de prostitutas, é o dilema da segunda destas que, a nosso ver, oferece os mais interessantes subsídios para a reflexão antropológica. Eis por que enquanto um Estado receptor pode ser completamente arbitrário em suas definições de prostituta, o Estado originário há de contrabalançar seus esforços nesse sentido com as devidas responsabilidades de garantir os direitos de suas cidadãs. Tipicamente, esse dilema é resolvido através da construção de uma segunda categoria que permite ao Estado exercer poder repressor e tutelar sobre uma determinada porção de suas emigrantes. Nas experiências históricas dos últimos cem anos no mundo atlântico, essa categoria tem sido predominantemente a da mulher traficada.

No presente trabalho, pretendemos apresentar um estudo da forma com que um Estado nacional tratou a questão da migração feminina “questionável”, empregando a categoria de traficada não para salvaguardar os direitos humanos e/ou constitucionais de suas cidadãs, e sim para sanear a reputação da nação em um momento em que projetos de expansão de status nacional estavam em destaque. O caso analisado aqui envolve um grupo de dançarinas estadunidenses trazidas ao Brasil durante a Primeira Guerra Mundial para trabalhar em teatros e casas noturnas no Rio de Janeiro. Ele é interessante pois, embora os funcionários do Departamento de Estado americano envolvidos na situação se referissem às mulheres como "traficadas", seus depoimentos e suas atividades em torno da questão nos permitem descobrir um complexo de valores morais e de interesses que subjaziam e informavam as suas ações, revelando a luta antitráfico no início do século XX como uma superfície de emergência, ${ }^{2}$ na qual discursos referentes à nação, à feminilidade e à organização dos povos se manifestaram. ${ }^{3}$

\footnotetext{
2 Definida por Foucault (1972, p. 41) como uma área cultural e social através da qual o discurso se manifesta.

3 Entendemos a organização dos povos como uma série de discursos referentes às supostas características básicas e imutáveis que supostamente formam “a essência” (biológica ou cultural) de um determinado povo e que podem ser utilizadas para situar aquele povo em uma estrutura hierárquica com referência a outros povos.
}

Horizontes Antropológicos, Porto Alegre, ano 15, n. 31, p. 75-99, jan./jun. 2009 


\section{0 passaporte e o tráfico de escravas brancas}

Poucos estudiosos das migrações transnacionais têm se detido na história do passaporte. Esse documento, sem o qual a migração transnacional se torna imensamente complexa, é um artefato razoavelmente novo, cuja história está intimamente ligada ao recrudescimento das fronteiras nacionais durante e depois da Primeira Guerra Mundial (Torpey, 2000, p. 111-121).

A universalização do passaporte como documento de identidade internacional aconteceu em um contexto no qual a vigilância sobre os movimentos transnacionais atingiu novos ápices. Como John Torpey (2000) adverte, com o avanço do Estado moderno e o declínio da servidão, da escravidão e de outras formas de trabalho forçado, o poder de autorizar ou proibir o movimento das pessoas foi retirado dos indivíduos e centralizado nas mãos dos Estados e do sistema internacional de Estados. A criação do sistema moderno de passaportes, dessa forma, "sinalizou a aurora de uma nova era nos assuntos humanos, em que os Estados individuais e o sistema internacional de Estados [...] monopolizaram a autoridade legítima para permitir os movimentos dentro e através de suas jurisdições”; tal monopolização manifestou determinados interesses, entre os quais podemos destacar uma maciça preocupação com a questão dos "homens sem mestre", ${ }^{4}$ ou seja, o indivíduo livre, sem raízes, em movimento, sem necessidade de prestar contas a ninguém (Torpey, 2000, p. 8-9, tradução nossa).

O sistema de passaportes era visto em grande parte como defesa contra a ameaça que esse indivíduo sem dono representava. É notável o fato de que o sistema tenha tomado suas feições atuais somente após a Primeira Guerra Mundial - ou seja, depois que a ameaça do inimigo externo concreto tinha sido afastada - e cresceu em paralelo com uma jurisprudência internacional que se configurou como uma defesa social contra duas “maldades” específicas que representavam a face dupla, engendrada, do indivíduo sem dono: o homem anarquista/bolchevique e a mulher prostituta/escrava branca (Deflem, 2002, p. 65-70). Para o fim do presente artigo, é obviamente essa personagem fêmea, a escrava branca e traficada, que é do nosso interesse.

4 Para uma discussão do conceito de "homens sem mestre” no contexto inglês, ver Beier (1985).

Horizontes Antropológicos, Porto Alegre, ano 15, n. 31, p. 75-99, jan./jun. 2009 
O consenso entre a grande maioria dos estudiosos do tópico é que o chamado tráfico de escravas brancas era essencialmente um mito cujo combate seguia as características clássicas de um pânico moral (Doezema, 2000; Grittner, 1990; Irwin, 1996; Ringdal, 2004, p. 313-320; Rosen, 1983, p. 112136. Para discussões sobre a questão no Brasil, ver Kushnir, 1996 e Rago, 1991. Para o conceito de pânico moral, ver Cohen, 1972). Como explica o pesquisador Brian Donovan (2006), narrativas hiperbólicas sobre o tráfico eram extremamente populares nos Estados Unidos no início do século XX. Tipicamente, tais narrativas relatavam a história de uma moça, supostamente "pura" e "inocente" (leia-se virgem), que é aliciada por figuras suspeitas (muitas vezes não-brancos) do submundo e que rapidamente cai num "mundo de degradação”, no qual é forçada a manter relações sexuais com uma série de homens repugnantes e socialmente inaceitáveis. Embora sem muito fundamento na realidade, tais histórias eram amplamente divulgadas pela mídia da época. Brian Donovan (2006), por exemplo, encontrou pelo menos 15 peças de teatro e seis filmes sobre escravidão branca produzidos nos EUA entre 1900 e 1920, além de incontáveis livros e panfletos.

A onda de indignação que essas narrativas ajudaram a criar foi responsável por pelo menos 30 investigações sobre prostituição em cidades norteamericanas nos anos anteriores à Primeira Guerra Mundial e por legislações, em cerca de 44 estados americanos, que proibiam ou limitavam a prostituição - até então, de acordo com Ruth Rosen (1983), algo considerado um delito menor na maior parte do território norte-americano. O pânico moral sobre o trafico de escravas brancas atingiu seu ápice nos EUA em 1910, quando o Ato Mann criminalizou o transporte de mulheres "para fins imorais" (Donovan, 2006, p. 1).

Nickie Roberts (1998, p. 299), em seu estudo sobre a história da prostituição, é categórica na descrição do fenômeno:

O “tráfico de escravas brancas”, supostamente um tráfico internacional organizado de mulheres, era uma fantasia vitoriana. [...] Os moralistas da classe média estavam convencidos de que um "tráfico de mulheres", operado por redes bem estabelecidas do submundo, estava ocorrendo bem debaixo dos seus narizes, e eles teriam pouca dificuldade em criar um pânico público sobre este ultraje não-existente. 
Donovan, mais ponderado, concorda essencialmente com a caracterização de Roberts. Embora seja impossível saber quantas mulheres de fato foram traficadas, tudo indica que o número das vítimas era bem pequeno, se por "traficada" quisermos indicar o tipo de experiência da "depoente típica” popularizada pelas narrativas de escravidão branca (moça raptada e transformada à força e a contragosto em prostituta). De acordo com Donovan (2006, p. 1-2, tradução nossa), essas narrativas não refletiam a realidade, mas "as condições históricas e sociais de sua produção":

O meio ambiente político, econômico e cultural da Época Progressiva [nos EUA] criou um solo fértil para a fixação dessas histórias na consciência pública. As narrativas de escravidão branca desenvolveram-se nos EUA durante um período marcado por urbanização rápida, o ingresso de um maior número de mulheres no mercado de trabalho e a mudança na composição racial das cidades americanas. Esses deslocamentos sociais convergiam nas narrativas de escravidão branca. A poética das histórias criou uma voz poderosa para a enunciação das preocupações acerca da velocidade e da direção da transformação social.

Nas narrativas do tráfico de escravas brancas estamos, então, cara a cara com as preocupações acerca do “indivíduo sem dono” que o sistema de passaportes foi criado para resolver, aqui tipificado pela mulher que está em trajetória de deslocamento do interior dos EUA e do mundo das afeições (a família) para a cidade e o mundo do trabalho. Tal deslocamento a coloca (nas palavras de um oficial consular americano, do qual falaremos mais adiante) longe do alcance de "seus protetores naturais" (isto é, o pai, o marido, os irmãos ou o líder religioso) e atinge seu ponto mais radical quando a trajetória é projetada para além da cidade, para o estrangeiro exótico, depravado e não-branco. Podemos ver um exemplo ${ }^{5}$ desse estilo de narrativa no musical Thoroughly modern Millie (1967), no qual a protagonista, moça do interior dos EUA, viaja para a cidade e, por pouco, não acaba nas garras de uma organização criminosa chinesa, especializada no extravio de mulheres brancas americanas para o exterior para fins de prostituição forçada (Donovan, 2006, p. 2).

5 Esse filme é ambientado em 1922 e, embora produzido em 1967, repete com fidelidade a narrativa de escravidão branca que era tão popular no início do século XX nos EUA. 
No início do século XX, a mulher, em sua trajetória em direção à modernidade e ao individualismo, era vista como especialmente vulnerável ao desvio, e teve de ter seus passos regulados pelo Estado. Esse era particularmente o caso quando sua trajetória a levava para além das fronteiras de seu país de origem e, em especial (no caso de mulheres brancas europeias e estadunidenses), quando tal percurso acabava em países entendidos como "não-brancos" - por exemplo, os países na nova fronteira de expansão imperial dos Estados Unidos na América Latina.

\section{Os EUA e a seducão da América do Sul na Belle Époque}

A Guerra Espanhola de 1898 serve como marca d'água para a segunda fase da expansão dos Estados Unidos na área cultural e geográfica conhecida como América Latina. ${ }^{6}$ Essa fase foi marcada por estratégias imperialistas mais tradicionais no Caribe e na América Central (com invasões, ocupações militares e o estabelecimento de regimes diretamente subordinados aos interesses de Washington), mas na América do Sul - e particularmente no Brasil - a expansão foi mais gradativa, progredindo pelos eixos de expansão econômica e de dominação do campo simbólico/cultural, de forma específica na área de entretenimento popular, com especial destaque para os filmes e a música (Rosenberg, 1982, p. 35-37; Tota, 2000, p. 13-21).

As repúblicas sul-americanas representavam um desafio para os Estados Unidos. Em primeiro lugar, elas eram grandes e distantes demais para serem militarmente conquistadas e ocupadas. Estavam também associadas a poderosos interesses europeus - destacadamente o Império Britânico. Por fim, configuravam espaços entendidos como não-brancos, dominados pela Igreja católica, portanto, seguindo a ideologia social darwinista da época, eram subevoluídos. No século XIX, de acordo com a historiadora Emily Rosenberg (1998, p. 500), esses países eram largamente entendidos pelos intelectuais americanos como moral e racialmente deficientes e incapazes de desenvolver governos ou mercados estáveis e modernos.

6 A primeira fase, é claro, veio antes da Guerra Civil Americana (1861-1865) e foi marcada pela Revolução Texana (1835) e a guerra com o México (1848). 
Todavia, com a expansão dos interesses comerciais americanos na região, começou a nascer uma outra ideologia, que se baseava numa releitura da antiga Doutrina Monroe. O “corolário Roosevelt à Doutrina Monroe” estabelecia as bases para um pan-americanismo que pregaria uma pretensa semi-igualdade entre as repúblicas do hemisfério, uma nova ordem em que os Estados Unidos assumiriam o papel de guia dos passos das demais nações - à força, se fosse necessário (Lefeber, 1989, p. 81-85, 218-230; Salvatore, 1998, p. 8182). Essa reformulação simbólica criou uma curiosa feminização das nações sul-americanas dentro do campo representacional norte-americano. Como salienta Ricardo D. Salvatore (1998, p. 83, tradução nossa), o pan-americanismo caracterizava esses países como "nações adultas”, mas feminizadas:

Entre 1890 e 1930, alguns países da América Latina - mais notavelmente a Argentina e o Brasil - integraram suas economias com os circuitos mercantis do Norte, recebendo cada vez mais bens norte-americanos em troca de exportações de matérias-primas. Como resultado, a América do Sul se transformou [no imaginário pan-americano] numa consumidora fêmea fascinada pelos bens e pela cultura da América do Norte, madura suficiente para casar-se com o capital e a cultura norte-americana. ${ }^{7}$

Salvatore (seguindo Stephen Greenblatt, 1991) caracteriza o discurso imperial dos EUA dessa época como uma "máquina de representações” (representational machine), "um conjunto de mecanismos, processos e aparatos que produz e circula as representações que constituam as diferenças culturais”; tais representações formaram a base do império tanto quanto o poder militar, econômico ou diplomático (Salvatore, 1998, p. 72, tradução nossa). Em sua construção de diferenças capazes de representar o poder e o prestígio dos EUA na América Latina, essa máquina, porém, não só circulava determinados indivíduos, certas histórias, imagens e representações, como também impedia outros de circularem.

No caso do Brasil, uma espécie de reconfiguração na população americana residente (permanentemente) no país aconteceu durante a primeira

Salvatore vai além, situando o Brasil e a Argentina como países que, nessa construção simbólica, teriam alcançado o status de "homens". Todavia, é mister salientar que esse processo levou algum tempo e só se completou no final do período em questão. Na época aqui retratada (1917-1918), o Brasil ainda estava bastante feminizado na imaginação imperial estadunidense.

Horizontes Antropológicos, Porto Alegre, ano 15, n. 31, p. 75-99, jan./jun. 2009 
metade do século XX. Ela aumentou de 649, em 1884, para 3.795, em 1940 (Blanchette, 2000, f. 136) e também se imperializou, configurando-se cada vez mais como uma colônia, claramente associada aos projetos de projeção de poder e status de seu país de origem em terra brasilis. Indícios desse processo podem ser vislumbrados nas publicações populares do Rio de Janeiro da época, com crescentes destaques para escolas, igrejas, festas americanas e, particularmente, para a contextualização dessas como integrantes da haute culture carioca. ${ }^{8}$ Todavia, se esse processo de imperialização, por um lado, envolvia a propagação de eventos e a celebração de indivíduos, famílias e instituições capazes de aumentar o prestígio dos EUA no Brasil, ele também envolvia a censura, a repressão e a expulsão dos elementos capazes de afetarem negativamente tal prestígio.

Um documento de 1946 da American Society of Rio de Janeiro ${ }^{9}$ (que tanto naqueles tempos quanto hoje reunia a elite da comunidade fluminenseamericana) nos revela essa dupla ação. Pleiteando o reconhecimento oficial do Departamento de Estado dos EUA para suas atividades no Rio de Janeiro, a Society destacou seus trabalhos patrióticos de apoio aos soldados e aos marujos americanos na cidade durante as guerras mundiais, e seus esforços para abrir os mercados brasileiros ao comércio estadunidense. Todavia, em outros documentos anexados ao pedido, a Society também caracterizou como obra patriótica suas tentativas de "remover os americanos vagabundos de praia" residentes no Rio de Janeiro e destacou o Consulado Geral dos EUA e a polícia da capital como aliados nessa empreitada (NARA, 1942). Infelizmente, a documentação disponível da Society não entra em maiores detalhes sobre essas atividades de profilaxia imperial, mas o que existe deixa claro que, na nova

8 Essa afirmação é baseada em análise dos arquivos das revistas Fon-Fon e $O$ Malho para o período de 1902-1920.

9 Documentos das embaixadas americanas (NARA, 1946). A informação sobre a remoção de vagabundos vem de um documento anexo, originalmente escrito pela Society em 1940: “[...] The most important function of the Society is the relief work. This, of necessity, receives less publicity than any other activities since the officers feel that this work should be done without calling unnecessary attention to it. This relief work is of three types: - one of which might be called negative and the other two, positive. The first consists of keeping the streets clean of beach-combers and other derelicts, who bring no credit to the American colony and who as a rule deserve little help. In this work we have received the cooperation of the American Consulate General and the Police Department [do Rio de Janeiro]. The positive types consist of actual relief extended to worthy individuals and advances made to people who are temporarily in need but who can probably reimburse the Society if given time."

Horizontes Antropológicos, Porto Alegre, ano 15, n. 31, p. 75-99, jan./jun. 2009 


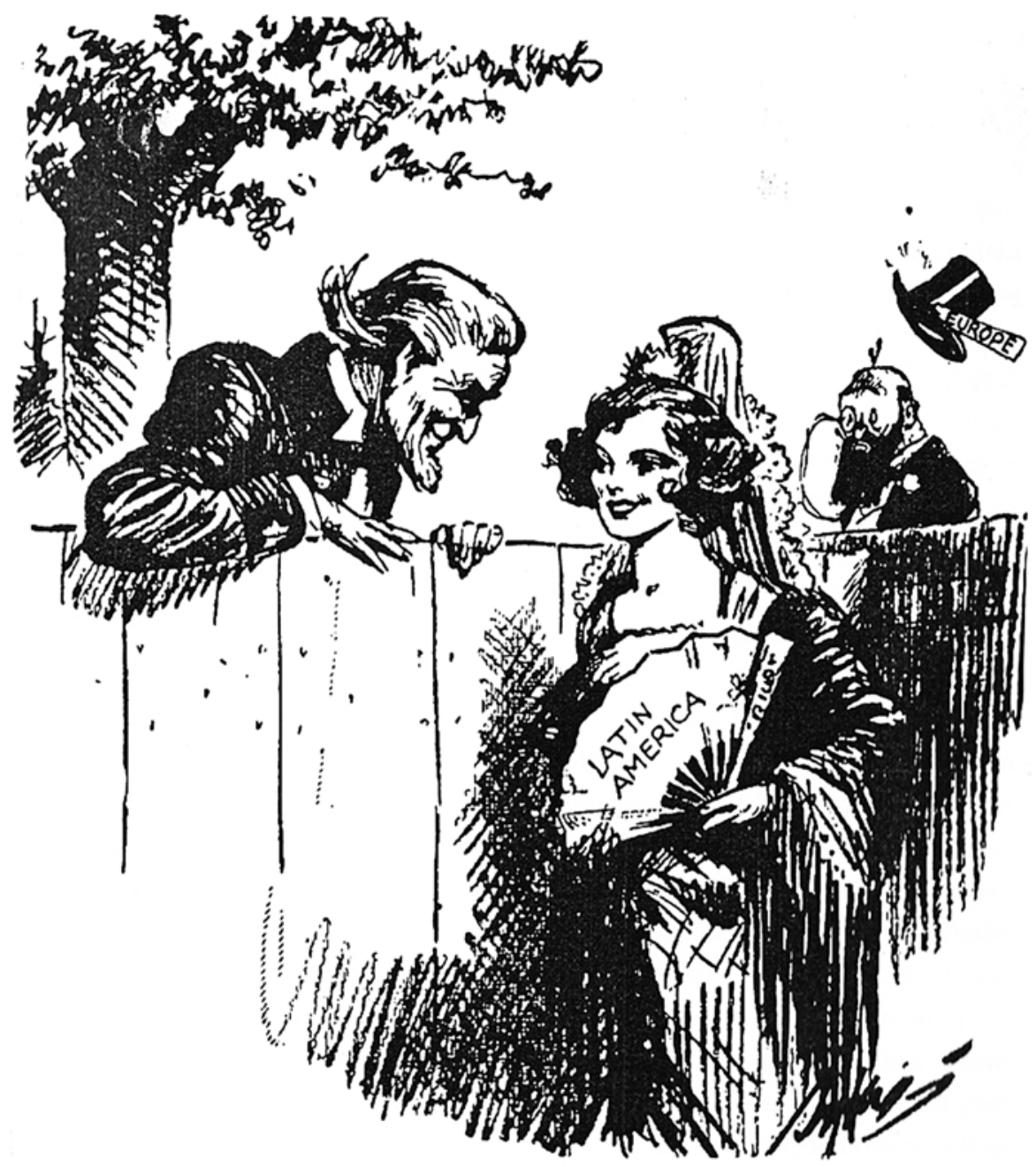

¿ykes, My, How You Have Grown!

i'hiladelphia Evening Public Ledger, 1923.

rourtesy of Philadelphia Inquirer.

Figura 2. "Nossa, como você como você tem crescido!" Tio Sam seduz a moça América Latina enquanto o velho Europa alarma-se com a cena. A charge (do Philadelphia Evening Public Ledger, de 1923) expressa a visão de uma América Latina amadurecida e feminizada, então corrente nos EUA (Pozas, 1998, p. 528). 
fronteira imperial dos EUA, certos tipos de americanos não eram bem-vindos e, se insistissem em firmar presença no Rio de Janeiro, encarariam uma aliança de forças oficiais (vindas da embaixada e da polícia local) e particulares (vindas da associação dos "bons americanos" residentes na cidade), aliança esta que os pressionaria a abandonar a Cidade Maravilhosa.

Resumindo, o crescente monopólio do Estado para (des)legitimizar os movimentos internacionais através do sistema de passaportes, o pânico moral em relação à escravidão branca e o nascente campo de lei internacional combinavam-se para intensificar a vigilância sobre o deslocamento de cidadãos americanos - em especial, das cidadãs. Simultaneamente, o crescimento da presença dos Estados Unidos na América do Sul, através da expansão de seu comércio e do aumento de seu prestígio cultural, criava uma espécie de imperialismo sedutor (nas palavras de Pedro Tota, 2000), em vez de conquistador. Para poder seduzir, as máquinas de representação desse imperialismo precisavam fazer circular determinadas imagens, histórias e pessoas, e também inibir outras de circular. Era de se esperar então que, se os “vagabundos” americanos não eram bem-vindos no Rio de Janeiro, suas primas "vagabundas" seriam ainda mais fortemente repelidas.

\section{As American girls}

No final de novembro de 1917, a Baxter and Willard Company, um grupo americano de vaudeville, ${ }^{10}$ composto de uma banda e dúzias de jovens dançarinas e cantoras, desembarcou para uma temporada no Rio de Janeiro, aceitando o convite de Djalma Moreira, dono do Teatro Phenix e do Clube Palace (também conhecido como International Club). A tropa foi muito bem recebida e os jornais e as revistas de variedades da cidade publicaram várias fotos das American girls e elogiaram o espetáculo por elas protagonizado. Como a revista Fon-Fon (1917a, p. 30) advertiu: “As American Girls [...] têm agradado no Theatro Phenix, apresentando originalíssimas dansas e cantos de seu paiz”.

10 Vaudeville e burlesque eram duas formas do teatro popular americano do início do século XX, de maneira geral, análogas ao teatro de revista carioca. 
Todavia, lendo as entrelinhas nas colunas de fofocas, podemos ver que a dança e o canto não eram as únicas coisas a serem oferecidas pelas girls. Segundo a Fon-Fon (1917a, p. 30), "As endiabradas american girls tem revolucionado parte da nossa jeunesse dorée. Louras na maioria, quasi todas fausses maigres, exhibindo á vontade as pernas, as buliçosas dansarinas tem tido sucesso sem precedente no Rio". Seu sucesso era pelo menos parcialmente atribuído ao fato de que o charme mais íntimo das girls era accessível, aparentemente, a determinados senhores abastados da boemia carioca. Na primeira semana de dezembro de 1917, a Fon-Fon reportou que a companhia Baxter and Willard já estava “desfalcada de 15 artistas”.

É quasi desnecessario dizer que pertencem ao bello sexo. As quinze artistas que deixaram o palco do Phenix para desfructarem ephemeros idylios em varios pontos do Rio fazem parte do trepidante grupo das american girls. (Fon-Fon, 1917b, p. 23).

A coluna de fofocas da Fon-Fon deliciava-se com as aventuras das girls - sempre bem acompanhadas por ilustres figuras masculinas da sociedade carioca - em suas viagens a Paineiras, Corcovado, Santa Teresa, Confeitaria Colombo e Teatro Municipal. Maliciosamente, o colunista da revista comparava o comportamento delas ao dos marujos americanos: "Não ha duvida, as american girls estão na ordem do dia e em toda parte como a jovial marinhagem dos navios de guerra do seu admiravel paiz, quando ancorados no nosso porto” (Fon-Fon, 1917c, p. 26). Desnecessário dizer qual era a reputação dos integrantes da marinha americana, sendo que em outros números da revista e de seus competidores eles eram constantemente caracterizados por seu grande apetite sexual (ver também O Malho, 1918).

A competidora da Fon-Fon, a revista $O$ Malho, ia mais além, publicando um artigo de Max Linder que ridicularizava a predileção da elite masculina carioca pelas girls. Intitulado "Originalíssima”, esse texto tomou forma de um diálogo entre dois homens e merece ser citado por extenso por causa das revelações mais explícitas que faz do comportamento das americanas e de seus pretendentes:

- Sabes que sou doido por tudo quanto é dos Estados Unidos.

- Sim. Conheço o teu entusiasmo pelos homens e pelas cousas da grande República... 
- Ah, meu caro! Tudo quanto é norte-americano é magnífico: não parece nada com o que há em outros paízes, é superior ao conhecido em todo o mundo. Pois muito bem. Não imaginas a ventura que me acaba de ser dada...

- Arranjaste uma nomeação para a América do Norte...

- Não tanto. Conquistei uma bailarina americana.

- Bravo!

- As bailarinas americanas são as melhores do Universo. E são as mulheres mais interessantes, mais arrebatadas e mais originais que já pisaram o Brazil e os corações dos Brazileiros que freqüentaram theatros - e especialmente camarins. Estupendíssimas!

- Vamos à conquista.

- Uma bailarina apaixonou-se por mim...

- Ou tu é que...

- A paixão foi mútua. O caso é que ella ficou mesmo pelo beiço...

- Bem dizes que as americanas são originaes...

- Muito. Andei a render-lhe homenagens uns dous dias. Mostrou-se esquiva. Confesso que já estava desanimado. Mandei-lhe então uma pulseira, que me custou dous contos. A rapariga, sensibilizada com a prova, não escondeu mais a inclinação que tinha por mim. $\mathrm{E}$ foi logo às do cabo. Os americanos não perdem tempo! Marcou-me uma entrevista, no hotel em que mora, que, por sinal, é de nossos bons hotéis onde são só admittidas famílias.

- Famílias? E ella lá está?

- Trata-se de uma exceção aberta como mais uma demonstração do nosso amor aos Estados Unidos. Ah! Se fosse de outra nação, lá não ficaria dez minutos...

- Bem. Marcou-te a entrevista.

- E eu lá fui. A mulherzinha recebeu-me como se fosse intima de dez annos. Não teve a menor cerimônia. Offereceu-me um jantar, ou antes mandou preparar-me um banquete de primeira ordem. Não posso dizer que m'o ofereceu porque fui eu quem o pagou. Houve champagne a rodo. E ella, sempre à vontade, tomou uma carraspana que... não te digo nada! Deu para cantar e dansar e fez um barulho de tal ordem que dahi a pouco havia gente a bater à porta. Quase veiu a polícia!

- Originalíssimo.

- No dia seguinte, continuando a não fazer cerimônias comigo, pediu-me um conto de réis pela manhâ. À tarde quis por força que lhe désse um collar que vira no Luiz de Rezende...

$-\mathrm{E}$ tu...

- Dei-lhó, é claro. Fomos depois passear de automóvel. A certa altura, quis champagne. Entramos numa confeitaria. Bebeu umas três garrafas. Voltamos. Quis tomar aperitivos na [Confeitaria] Colombo. Lá fomos. Alli a cousa esquentou, 
com a mistura das bebidas. E, de repente, levando mal os olhares de certa rapariga, que estava numa mesa próxima, não esteve com uma nem duas: levantou-se e esmurrou-a antes que eu podesse intervir. $\mathrm{O}$ cavalheiro que acompanhava a agredida tomou a defesa d'esta - mas achou que devia faze-lo, metendo-me a bengala. Reagi com uma cadeira, que lhe arrumei nas costas. Fechou-se o rolo. Acabamos na polícia onde fui obrigado a postar fiança para que minha adorada bailarina não ficasse presa.

- Muito interessante...

- Original, pois não é?

- Mas tú, à vista do ocorrido, achas-te conveniente dar por terminada a paixão...

- Que! Fiquei firme. Não calculas a série de cousas que houve depois. Gastei dinheiro à bessa. O diabrete, sempre original, exigia-me presentes que custavam os olhos da cara. Eu hesitava em attender-lhe os desejos, declarava-me, com muita graça, que, no dia seguinte, não me receberia mais. Impagável!

- Vê-se que as bailarinas americanas não se parecem nada com as bailarinas ou não de outras nacionalidades....

- Inconfundíveis! Mas ouve o resto. Quanto a pileques, aquillo era um por dia. E já se sabe: davam sempre em resultado fortes escândalos. Às vezes, à hora de começar o espectáculo, batia a pé e não entrava em scena. Era uma patuscada. Havia muita, e grossa, que eu é que tinha de pagar... Correu o negócio assim até que um dia, vendo que não havia dinheiro que chegasse para lhe satisfazer os caprichos, recusei-me, com pretexto qualquer, a asignar-lhe um cheque. Pois muito bem. Foi isso pela manhâ. À tarde, quando fui ve-la, encontrei-a em companhia de outro homem, muito contente, a beber champagne. Levantou-se, e disse-me que me puzesse ao fresco quanto antes, se não queria me atirasse uma garrafa à cara.

- E que fiz este?

- Ri-me e sahi. Originalíssima!

Decididamente, as bailarinas americanas não se parecem com as de qualquer outro paiz... (Linder, 1917).

O texto acima nos fornece uma série de informações interessantes a respeito das girls e de seus pretendentes. Em primeiro lugar, elas se comportavam como as prostitutas de luxo cariocas da época. Em seu estudo sobre a prostituição no Rio de Janeiro no final do século XX, Magali Engels Vainfas (1985, f. 41-42) chama a atenção para essa categoria de prostituta que muitas vezes trabalhava como dançarina ou "artista" e freqüentava "os 'music-halls' [...] as casas de chope, os cafés-concertos [...] [e as] confeitarias e teatros”. A 
graça do artigo de Linder reside no fato de que as "originalíssimas” American girls agiam exatamente como as "bailarinas ou não de outras nacionalidades" residentes no Rio de Janeiro de então. O incidente na Confeitaria Colombo é especialmente relevante nesse contexto, uma vez que Vainfas (1985, f. 42) afirma que “a freqüência da 'Colombo' dividia-se em dois horários que eram observados com rigor: entre 14 e 17 horas o público era constituído pelas 'senhoras de família’ e, a partir das 17 horas e 30 minutos começavam a chegar as 'prostitutas'”. O lugar, portanto, era frequentado por duas categorias morais de mulher, que eram aparentemente separadas por regras costumeiras e rígidas que diziam respeito ao horário de frequência de cada grupo. Podemos levantar a hipótese de que a americana e seu pretendente violaram essas regras, chegando no horário "de família” enquanto a americana agia como uma "mulher pública”. Alternativamente, a americana poderia ter entrada na briga com uma prostituta nativa. De qualquer maneira, a escolha da Colombo como cenário para o confronto é significante em termos da classificação moral da dançarina.

Em segundo lugar, o artigo e as ilustrações que o acompanham deixam claro que os homens que disputavam o charme das girls eram da elite carioca. Linder tipifica-os como "entusiastas” da república norte-americana, considerando-a uma potência emergente e uma fonte de inovações. $\mathrm{O}$ autor contrasta a "grandeza” dos EUA com a vulgaridade das dançarinas, comentando acerbamente que elas tinham permissão de residir num "hotel de família” apenas em razão do grande prestígio que aquele país usufruía na capital federal brasileira. Podemos então encarar o texto de Linder como um discurso que ironizava as imagens produzidas pelas máquinas de representação do poder imperial americano. Aqui, vemos os EUA e os americanos descritos como "magníficos”, "superiores”, “originais” e "os melhores do universo”, no entanto, suas girls comportavam-se exatamente como as prostitutas cariocas ou "de outros países”. Até os valores referentes à impetuosidade e à originalidade americana eram invertidos no artigo, com a dançarina "não perdendo tempo" (pois como todo americano sabe, tempo é dinheiro) e "sem a menor cerimônia” indo diretamente ao que interessava: negócios. A graça do "Originalíssima” reside no fato de as dançarinas de Baxter and Willard serem, enfim, tão comuns.

É mister lembrar nesse contexto que as tentativas dos Estados Unidos mobilizarem as Américas na Primeira Guerra Mundial tinham sido calcadas na noção de que os EUA trariam um novo e original sopro de valores

Horizontes Antropológicos, Porto Alegre, ano 15, n. 31, p. 75-99, jan./jun. 2009 
democráticos e morais à guerra. A propaganda americana da época situava os interesses do país na guerra como "diferentes” daqueles dos demais participantes, pois supostamente os EUA tomaram a decisão de lutar contra as Potências Centrais para protegerem os direitos de navegação dos países neutros e, mais tarde, para assegurarem a governança democrática da Europa.

A presença das American girls no Rio de Janeiro e seu sucesso entre a jovem elite da cidade desafiavam as representações produzidas pelo imperialismo americano. As girls simbolicamente associavam os Estados Unidos, suas inovações e suas culturas com o meretrício feminino, justamente no momento em que aquela nação tencionava forjar uma coalizão do hemisfério, sob a sua liderança, para intervir na Primeira Guerra Mundial. É interessante notar que um dos assuntos largamente discutidos nos jornais e nas revistas cariocas, na mesma época do escândalo das girls, era a forma que a intervenção panamericana na guerra iria tomar. Os Estados Unidos sustentavam a posição de que deveriam intervir ativamente no conflito, enquanto as demais repúblicas americanas ajudariam a sustentar a força bélica dos aliados com suplementos e matérias-primas. O número de $1^{\circ}$ de dezembro de 1917 de $O$ Malho publicava uma charge criticando essa posição, com Tio Sam explicando que ele "resolveria a briga” e Jeca (representando o Brasil) "cuidaria da boia”. Tal atitude era largamente vista como fruto de certa arrogância americana e, talvez por essa razão (entre outras), o espetáculo de dúzias de moças americanas comportando-se "modernamente" e "virilmente" feito marujos - ou melhor ainda, como as dançarinas polacas, "francesas" e mulatas, tão frequentemente encontradas nas ruas do Rio de Janeiro de então - deliciava o público carioca. Enfim, o que é que a americana - ou o americano - tinha de tão especial?

\section{0 império contra-ataca}

A presença das American girls no Rio de Janeiro não tardou a suscitar reação do corpo diplomático americano. No dia 28 de janeiro de 1918, o cônsul-geral dos Estados Unidos no Rio de Janeiro enviou um relatório ao secretário de Estado ${ }^{11}$ americano descrevendo o problema e as medidas que

11 O ministro federal que controla o Departamento do Estado - o Itamarati dos EUA.

Horizontes Antropológicos, Porto Alegre, ano 15, n. 31, p. 75-99, jan./jun. 2009 
foram tomadas para enfrentá-lo, e fazendo sugestões para evitar tais situações no futuro.

O documento iniciava caracterizando o grupo Baxter and Willard como "uma companhia ordinária de burlesque ou vaudeville americano, cujos membros são majoritariamente fêmeas e recrutadas pelas agências mais baratas de vaudeville” (NARA, 1918, tradução nossa). A presença da tropa no Brasil foi explicada pela aproximação entre este país e os EUA e pela expansão e possibilidade de alcance da cultura americana no Brasil. A grande popularidade do cinema americano, em particular, foi citada como o fator que teria preparado o terreno para as viagens de companhias de teatro ao Brasil, "até então raras”.

De acordo com o cônsul-geral, essa situação era problemática, pois "uma companhia de burlesque normal, que faz shows nas casas de ópera de 20 e 30 centavos em nosso país [os EUA] tem, muitas vezes, normas elásticas de moralidade".

Transplantar uma agremiação desse tipo, cheia de jovens americanas bonitas, com poucas reticências e que são ambiciosas para fazer seu caminho no mundo e se divertirem tanto quanto possível, invariavelmente pressupõe a possibilidade de problemas. É proverbial a tendência dos jovens ricos sul-americanos para pegar, dos coros das companhias viajantes, amantes e para gastar relativamente grandes somas de dinheiro com as mulheres dessa classe. (NARA, 1918, tradução nossa).

O problema "pressuposto" não era então que as girls estivessem sendo "traficadas" contra a sua vontade, nem que seus direitos fossem violados: o problema era, simplesmente, que muitas delas iriam se engajar em relações sexuais com a elite nativa em troca de dinheiro. A associação do grupo Baxter and Willard com Djalma Moreira abriria amplas possibilidades para esse tipo de comportamento, já que Moreira era dono de um clube que atraía "um público de jogadores baratos [...] viajantes comerciais, outros turistas, jovens boêmios e a classe menos ofensiva de meretrizes" - muitas das quais "vivem através da mesa de jogo quando não têm um protetor temporário para pagar suas contas". Após seus shows, as jovens americanas frequentavam o clube de Moreira, “onde, como é o costume de todas as mulheres não-acompanhadas, elas recebem seus jantares sem terem de pagar - presumivelmente em consideração por terem amigos homens que consumirão e pagarão as bebidas” (NARA, 1918, tradução nossa). 
O cônsul conversou com Mr. Baxter e descobriu que o dono da tropa não estava disposto a censurar a moralidade de suas funcionárias, "sendo que ele quer que elas se divirtam e não se ausentem do palco”. Baxter não forçava as jovens a ir ao clube de Moreira, mas afirmou que a "inclinação natural" delas seria frequentar um ou outro clube desse tipo e, mantendo-as no Palace, ele "poderia vigiá-las e prevenir sua associação com indivíduos masculinos perigosos”. Em outras palavras, Baxter estava a fim de ganhar dinheiro e não de proteger a moral ou a reputação de suas funcionárias.

Mas a verdadeira ameaça que as girls representavam para o projeto imperial americano não era em função dos programas eventuais que elas pudessem fazer durante sua viagem, e sim a possibilidade de que escapassem do controle de Mr. Baxter, fixando residência no Brasil por um tempo indeterminado e estabelecendo-se como prostitutas locais.

Esse problema foi exemplificado pelo caso da jovem dançarina Mary Wilson, que resolveu se ausentar das apresentações do grupo para ser a companheira de Frederico Haas (ou Merat), descrito como "um homem de negócios da classe baixa e um rufião" - ou, em bom e velho carioquês, um malandro. Wilson aparentemente deixou o grupo Baxter and Willard para trabalhar como prostituta para Haas e foi presa, bêbada, "numa pocilga nas margens da cidade”. Sendo americana, seu caso não foi tratado como o das prostitutas normais da época: ela foi encaminhada pelo cônsul ao sanatório Dr. Eiras, em Botafogo. Todavia, seu companheiro Haas liberou-a e, em seguida, Wilson apareceu no Consulado Americano à procura de seus pertences (que tinham sido confiscados pelo cônsul). Eles foram devolvidos com certa má vontade, pois, de acordo com o cônsul-geral, era impossível e ilegal mantê-los em sua posse, sendo Wilson maior de idade. O cônsul aparentemente aproveitou a visita de Wilson para adverti-la sobre os riscos que ela estava correndo, deixando para trás a proteção de seu empregador em terras estranhas, pois ouvira em troca a afirmação da jovem de que "ela estava entrando na vida ${ }^{12}$ por sua livre e espontânea vontade e gostava disto”.

O caso Wilson era a principal razão pela qual o cônsul-geral escrevia ao secretário de Estado americano, denunciando o que ele chamava de "essa variante ainda mais sutil e insidiosa de escravidão branca”. Todavia, o problema

12 “The life” em inglês, um eufemismo comum na época para a prostituição.

Horizontes Antropológicos, Porto Alegre, ano 15, n. 31, p. 75-99, jan./jun. 2009 
representado por Wilson não era as eventuais coações que a jovem poderia encontrar no Brasil, e sim a ameaça que ela significava para as representações do poder imperial americano. O cônsul deixou esse ponto claríssimo no final de seu relatório, ao fazer recomendações para a resolução de futuros casos do mesmo tipo:

Tenho viajado pela Índia Britânica a serviço de nosso governo. Lá, tenho visto que um homem pode obter, em troca do dinheiro, mulheres de toda a nacionalidade, menos as inglesas. Na Î́ndia Britânica, a prostituta inglesa, ou a mulher que parece estar vulnerável à prostituição, é instantaneamente deportada. Os britânicos que dominam a Índia pensam, corretamente, que nenhum nativo deve poder dizer que ele tem gozado das atenções de uma mulher da casta dominante ou superior. [...] Embora reconheça que possa ser difícil tomar esse tipo de atitude com respeito à América Latina, tenho a honra de, urgentemente e também respeitosamente, convocar a atenção do Departamento [de Estado] para uma nova fase do problema social que estamos enfrentando ao tratar com esses países [...]. (NARA, 1918, grifo do autor, tradução nossa).

Encontramos aqui uma afirmação do projeto imperial sendo implementado na América do Sul pelos EUA e a sua clara articulação com o comportamento sexual de cidadãs americanas na região. Nessa acepção, os EUA devem dominar a América Latina de uma maneira análoga à da Grã-Bretanha na Índia. Tal dominação resultará em populações claramente ordenadas em superiores e dominantes (americanas) e inferiores e dominadas (latinas) e, segundo essa ordenação, a sexualidade das mulheres do grupo superior teria que ser rigorosamente controlada para que nenhuma delas “caísse” nas mãos dos homens do grupo inferior - pelo menos fora das relações matrimoniais. ${ }^{13}$ Aqui exposto está o verdadeiro problema representado pelas American girls: ao forjarem relações sexuais comerciais com as "castas inferiores” da América Latina, elas enfraqueceram as representações de status nacional que situava os EUA como uma força dominante na região.

${ }^{13}$ Nem todos os relacionamentos entre latino-americanos e estadunidenses eram problemáticos, pois o cônsul aparentemente aceitava os casamentos de mulheres americanas com membros estabelecidos da elite carioca. Todavia, é mister lembrar que as American girls não estavam se engajando em prostituição com homens das classes populares, e sim “jovens da elite”. O nexo do problema, então, eram as relações sexuais comerciais, seja com quem fossem conduzidas. 
Ciente da ameaça, o cônsul-geral americano sugeriu que no futuro "qualquer empecilho que a Divisão de Passaportes [Passport Bureau] pudesse colocar no caminho de organizações teatrais americanas [como a Baxter and Willard Company] poderia se tornar uma obra de utilidade patriótica”. No caso dos grupos que eventualmente transpusessem essas barreiras, o cônsul sugeriu que seus gerentes deveriam assinar um termo de responsabilidade em relação às suas funcionárias femininas, sendo forçados a reportar qualquer deserção de uma delas do grupo. Em casos assim, o Consulado Americano deveria ameaçar a mulher em questão com a perda de sua cidadania americana.

Podemos perceber que as sugestões do cônsul foram levadas a sério pelo governo americano, pois anexado ao relatório está um memorando do Bureau de Cidadania americana (Citizenship Bureau), em que a questão da revogação foi aparentemente levada a sério, e cujo autor confirma "que devemos ser rigorosos e difíceis na emissão de passaportes para vagabundas dessa estirpe, especialmente quando elas estão viajando para os países da América Latina”.

\section{Conclusão}

A prostituição de mulheres americanas no Rio de Janeiro, vista pelos funcionários do Departamento do Estado, não era dessa forma uma questão de direitos humanos, e sim de prestígio dos EUA, pois permitia que "os nativos" pudessem "gozar das atenções de uma mulher da casta superior”. A América Latina, subordinada e feminizada nas representações sobre o poder estadunidense na região, não poderia abranger indivíduos americanos cujo comportamento pessoal colocava tais representações em dúvida. As atividades das girls na prostituição de luxo, como Linder (1917) notava, serviam como um foco particularmente aglutinador de discursos em que os “originalíssimos” americanos - viris, másculos e inovadores - poderiam se transformar em meretrizes comuns, nada originais.

Diante desse dilema, o Departamento de Estado mobilizava a categoria escravidão branca não para resguardar os direitos das mulheres americanas na região, mas sim para policiar sua sexualidade e seus corpos, mantendo-os dentro dos limites permitidos pelas representações do poder americano. Proteção de cidadãs vulneráveis significava então limitar os movimentos de "mulheres suspeitas” e - quem sabe - ameaçá-las com a revogação de sua cidadania, 
caso elas transpusessem os limites impostos por seu governo de origem. Na análise final, o protegido aqui era o Estado americano - ou, mais precisamente, as representações de seu novo poder imperial na América Latina.

\section{Referências}

AUGUSTÍN, L. M. Sex at the margins: migration, labour markets and the rescue industry. London: Zed Books. 2007.

BEIER, A. L. Masterless men: the vagrancy problem in England 1560-1640. London: Meuthen. 1985.

BLANCHETTE, T. Gringos. Tese (Mestrado em Antropologia)-Programa de Pós-Graduação em Antropologia Social, Museu Nacional/Universidade Federal do Rio de Janeiro, Rio de Janeiro, 2000.

BRENNAN, D. What's love got to do with it?: transnational desires and sex tourism in the Dominican Republic. Durham: Duke University Press, 2004.

COHEN, S. Folk devils and moral panics. London: Mac Gibbon and Kee, 1972.

DEFLEM, M. Policing world society: historical foundations of international police cooperation. Oxford: Oxford Press, 2002.

DOEZEMA, J. Loose women or lost women? The re-emergence of the myth of 'white slavery' in contemporary discourses of 'trafficking in women'. Gender Issues, v. 18, n. 1, p. 23-50, Winter 2000.

DONOVAN, B. White slave crusades: race, gender, and anti-vice activism, 1887-1917. Normal Illinois: University of Illinois Press, 2006.

FON-FON: Semanario Illustrado. Rio de Janeiro, anno 11, n. 48, 1 dez. 1917a. Disponível em: <http://objdigital.bn.br/acervo_digital/div_periodicos/fonfon/ fonfon_1917/fonfon_1917_048.pdf>. Acesso em: 30 out. 2008.

FON-FON: Semanario Illustrado. Rio de Janeiro, anno 11, n. 49, 8 dez. 1917b. Disponível em: <http://objdigital.bn.br/acervo_digital/div_periodicos/fonfon/ fonfon_1917/fonfon_1917_049.pdf >. 
FON-FON: Semanario Illustrado. Rio de Janeiro, anno 11, n. 50, 15 dez. 1917c. Disponível em: <http://objdigital.bn.br/acervo_digital/div_periodicos/ fonfon/fonfon_1917/fonfon_1917_050.pdf >. Acesso em: 30 out. 2008.

FOUCAULT, M. The archaeology of knowledge \& the discourse on language. New York: Pantheon Books, 1972.

GREENBLATT, S. Marvelous possessions: the wonder of the New World. Chicago: University of Chicago Press, 1991.

GRITTNER, F. K. White slavery: myth, ideology, and American law. New York: Taylor \& Francis. 1990.

IRWIN, M. A. "White slavery" as metaphor: anatomy of a moral panic. [1996]. Disponível em: <http://userwww.sfsu.edu/ epf/1996/wslavery.html>. Acesso em: 30 out. 2008.

KUSHNIR, B. Baile de máscaras. Rio de Janeiro: Imago, 1996.

LATOUR, B. Ciência em ação: como seguir cientistas e engenheiros sociedade afora. São Paulo: Unesp, 2000.

LEFEBER, W. The American Age: United States foreign policy at home and abroad since 1750. New York: W.W. Norton, 1989.

LINDER, M. Originalíssima. O Malho, Rio de Janeiro, p. 21-22, 8 dez. 1917.

NARA, RG 84. Foreign service Posts of the Department of State: Brazil: Rio de Janeiro Embassy. U.S. Secretary of State to Consul General, Rio de Janeiro, 1 fev. 1918. This is a handwritten note attached to the document containing correspondence dated 28 jan. 1918, referred to below.

NARA, RG 84. Foreign Service Posts of the Dept. of State: Brazil: Rio de Janeiro Embassy: Box 146. Prescott Childs to George Black, 22 jul. 1942.

NARA, RG 84.2. Unclassified and Classified Documents: Rio de Janeiro Embassy: Box 367. “American Society of Rio de Janeiro”, 1946. 
PISCITELLI, A. On gringos and natives: gender and sexuality in the context of transnational sex tourism in Forteleza Brazil. Vibrant, v. 1, n. 1, 2004. Disponível em: <http://www.vibrant.org.br/downloads/a1v1_ogn.pdf>. Acesso em: 30 out. 2008.

POZAS, M. del C. S. From reading to seeing: undoing imperialism in the visual arts. In: SALVATORE, J., et al. (Org.). Close encounters of empire: writing the cultural history of U.S.-Latin American relations. Durham, NC: Duke University Press, 1998. p. 525-556.

RAGO, M. Os prazeres da noite. São Paulo: Paz e Terra, 1991.

RINGDAL, N. J. Love for sale. New York: Grove Press, 2004.

ROBERTS, N. As prostitutas na História. Rio de Janeiro: Rosa dos Tempos, 1998.

ROSEN, R. The lost sisterhood: prostitution in America, 1900-1918. Baltimore: The Johns Hopkins University Press, 1983

ROSENBERG, E. Spreading the American dream: American economic and cultural expansion, 1890-1945. New York: Hill and Wang, 1982.

ROSENBERG, E. Turning to Culture. In: SALVATORE, J. et al. (Org.). Close encounters of empire: writing the cultural history of U.S.-Latin American relations. Durham, NC: Duke University Press, 1998. p. 497-514.

SALVATORE, R. D. The enterprise of knowledge: representational machines of informal empire. In: SALVATORE, J., et al. (Org.). Close encounters of empire: writing the cultural history of U.S.-Latin American relations. Durham, NC: Duke University Press, 1998. p. 69-106.

SILVA, A. P. da; BLANCHETTE, T. "Nossa Senhora da Help”: sexo, turismo e deslocamento transnacional em Copacabana. Cadernos Pagu, Campinas, n. 25, p. 249-280, 2005.

THOROUGHLY Modern Millie. Direção: George Roy Hill. Roteiro: Richard Morris. Los Angeles: Universal Pictures, 1967. 139 min, color., $70 \mathrm{~mm}$. 
TORPEY, J. The invention of the passport: surveillance, citizenship and the State. Cambridge: Cambridge University Press, 2000.

TOTA, A. P. O imperialismo sedutor: a americanização do Brasil na época da Segunda Guerra. São Paulo: Companhia das Letras, 2000.

VAINFAS, M. E. Meretrizes e doutores: o saber médico e a prostituição na cidade do Rio de Janeiro, 1845-1890. Dissertação (Mestrado em História)-Programa de Pós-Graduação em História, Universidade Federal Fluminense, Niterói, 1985.

Recebido em: 30/10/2008

Aprovado em: 16/12/2008 